\title{
JEAN GOLDZINK et GÉRARD GENGEMBRE, Madame de Staël, la femme qui osait penser
}

\section{Michel Arrous}

\section{OpenEdition}

\section{Journals}

Édition électronique

URL : http://journals.openedition.org/studifrancesi/16470

DOI : 10.4000/studifrancesi. 16470

ISSN : 2427-5856

\section{Éditeur}

Rosenberg \& Sellier

\section{Édition imprimée}

Date de publication : 1 juillet 2019

Pagination : 169

ISSN : 0039-2944

\section{Référence électronique}

Michel Arrous, " JeAn goldzink et géraRd gengembre, Madame de Staël, la femme qui osait penser », Studi Francesi [En ligne], 187 (LXIII | I) | 2019, mis en ligne le 01 juillet 2019, consulté le 25 janvier 2021. URL http://journals.openedition.org/studifrancesi/16470; DOI : https://doi.org/10.4000/studifrancesi. 16470

Ce document a été généré automatiquement le 25 janvier 2021.

\section{(c) (i) (9)}

Studi Francesi è distribuita con Licenza Creative Commons Attribuzione - Non commerciale - Non opere derivate 4.0 Internazionale. 


\title{
JEAN GOLDZINK et GÉRARD GENGEMBRE, Madame de Staël, la femme qui osait penser
}

\author{
Michel Arrous
}

\section{RÉFÉRENCE}

JEAN GOLDZINK et GÉRARD GENGEMBRE, Madame de Staël, la femme qui osait penser, Paris, Classiques Garnier, 2017, 303 pp.

1 On accordera volontiers aux co-auteurs le droit de reconnaître en Germaine de Staël le meilleur écrivain de l'ère impériale et la plus grande intellectuelle européenne. On leur sait gré aussi d'avoir adopté une démarche qui, sans être anti-biographique, saisit les œuvres dans leur flux et leur genre en se gardant de commentaires envahissants. Donc, point de parasitage critique et, plutôt que la narration de la vie de l'auteur, l'analyse de ses œuvres sous la forme d'hypothèses de lecture. En guise d'ouverture, un exemple de la méthode donné en 2012 par J. Goldzink dans Mme de Staël et sa correspondance: alors que bien des Correspondances générales sont lues comme des avant-textes ou des soustextes, les lettres de Mme de Staël, où jamais elle n'apparaît en littérateur professionnel, sont «un instrument substitutif de la conversation orale», sans néanmoins qu'en soient absents les confidences, les élans ou les dépits amoureux.

On aborde la partie «CEuvres» avec deux textes anonymes, les Lettres sur les ouvrages et le caractère de J.-J. Rousseau (publiées «sans [s]on aveu» en 1788) et les Réflexions sur le procès de la reine par une femme (1793). Les Lettres, où s'entend déjà une voix de femme, sont un éloge académique rédigé par un jeune auteur qui fait de nombreuses impasses sur l'œuvre philosophique de Rousseau, mais se montre passionné par les questions de morale, et, enthousiasmé par La Nouvelle Héloïse, défend le talent de Rousseau. Dans son appréhension de l'œuvre et du «caractère» de Rousseau, G. de Staël procède par empathie et raisonnement logique, même s'il arrive que l'empathie vire à la sensiblerie 
moralisatrice. Le deuxième écrit est une plaidoirie philosophique adressée en priorité aux femmes. Suivent (pp.57-75) deux autres essais en prise avec l'actualité: Des circonstances actuelles qui peuvent terminer la Révolution et des principes qui devraient fonder la République en France, abandonné inachevé en 1798, et les célèbres Considérations sur la Révolution française, le dernier ouvrage de Mme de Staël, publié après sa mort, où elle revient vingt ans plus tard sur la Révolution. Dans Des circonstances..., qui n'est pas un traité politique ni une proposition de réforme, elle prend acte du fait républicain et se demande comment stabiliser le régime directorial, alors que s'opposent durement les royalistes et les républicains, deux classes ennemies qui comptent chacune leur lot de fanatiques. Elle expose les moyens d'achever la Révolution en pacifiant la République, c'est-à-dire en abandonnant le système dictatorial. Dans les Considérations, la fille se rappelle le programme de son père et suggère de réconcilier les pouvoirs du tiers, de la noblesse et du roi, en excluant le bas-peuple du cercle électoral, les droits politiques devant reposer sur la propriété. On comprend que son projet c'est la «monarchie limitée», à l'anglaise. Sous l'intitulé Tableaux de la culture européenne (pp. 77-125) un important ensemble traite de la place et du rôle de l'auteur de De la Littérature et de De l'Allemagne. Son coup d'éclat n'est pas une histoire de la littérature européenne, mais plutôt une réflexion sur les principes de son intelligibilité, à partir de l'opposition entre Nord et Midi. S'y ajoute le souci d'une littérature «accordée aux suites de la Révolution française». Du programme exposé dans ce premier grand livre, Mme de Staël va donner une illustration en deux volumes avec le tableau d'une «littérature du Nord», l'Allemagne étant préférée à l'Angleterre parce que bien moins connue en France où elle est l'objet de préjugés violents. D'où le choix d'informer les Français des choses allemandes. Sont caractérisées dans leurs traits principaux la production de la pensée et les théories philosophiques, sans oublier l'enthousiasme - i.e. l'idéalisme -, à ne pas confondre avec le fanatisme! Tout au long de l'ouvrage se lit une critique de la culture française corrompue par la dégradation sensualiste. Sont aussi convoqués les deux romans dans leurs liens avec l'Histoire, mais aussi comme deux histoires de l'amour impossible et de la douloureuse destinée féminine (La femme et l'Histoire au miroir du roman, pp. 127-147). Dans Delphine l'insertion de l'Histoire se fait par des «implants» dans le récit fictionnel (dates, événements ou références à des événements historiques, lettres politiques); dans Corinne, le rapport à l'Histoire diffère quelque peu car le discours romanesque sur l'art et l'Histoire est pris en charge par les personnages, jusqu'à se développer parfois en d'amples méditations. Sans s'éloigner de la politique, on revient finalement à la question de l'autobiographie avec la figure de l'intellectuelle persécutée qui, comme le dit J. Goldzink, «semble a priori plus apte à analyser (des sentiments et des idées) qu'à narrer (des faits et des êtres)». Quelques traits essentiels de l'écriture mémorialiste sont choisis pour évoquer dans La voix et la mémoire (pp. 149-157) Dix Années d'exil, soit les années 1800-1804 et 1810-1812, ces dernières marquées par l'interdiction de De l'Allemagne et l'ordre d'exil, et par la découverte de la Russie.

3 On mentionnera rapidement la deuxième partie («Problèmes», pp. 175-288) car elle regroupe huit articles de G. Gengembre et J. Goldzink écrits à quatre mains entre 1988 et 2012 et bien connus des spécialistes, sur l'interprétation staëlienne de la Révolution, l'écriture de l'Histoire, sur De la Littérature comme texte théorique et produit de l'Histoire, et sur l'expérience européenne d'une femme qui n'a jamais séparé la littérature de l'Histoire ni la politique de la morale. 